\title{
Consumo, produção e composição do leite e do queijo de vacas alimentadas com níveis crescentes de ureia*
}

\section{Intake, production and processing of milk from cows fed increasing levels of urea}

Ana Cássia Rodrigues de Aguiar, ${ }^{* *}$ Celio Roberto Oliveira, ${ }^{* *}$ Luciana Albuquerque Caldeira, ${ }^{* *}$ Vicente Ribeiro Rocha Júnior, ${ }^{* *}$ Suely de Jesus Oliveira, ${ }^{* *}$ Camila Soares, ${ }^{* *}$ Deiyse Alves Silva, ${ }^{* *}$ Jordana Carvalho de Menezes, ${ }^{* *}$ Lucas Daniel Alcântara Borges ${ }^{* *}$

\begin{abstract}
Resumo
Objetivou-se por meio deste trabalho avaliar consumo, produção e processamento do leite de vacas alimentadas com dietas contendo níveis crescentes de ureia. Foram utilizadas 8 vacas $7 / 8$ Holandês/Gir em dois quadrados latinos 4x4, sendo cada quadrado composto de quatro dietas, quatro vacas e quatro períodos experimentais. As dietas foram formuladas para serem isoproteicas, tendo como volumoso a silagem de cana-de-açúcar. Os tratamentos consistiram em níveis crescentes de ureia em substituição ao farelo de soja $(0 ; 0,58 ; 1,17,1,75 \%$ na MS total da dieta). Os consumos de matéria seca e fibra em detergente neutro não foram afetados pelos níveis crescentes de ureia. Entretanto, o consumo de proteína bruta e extrato etéreo reduziram linearmente com o aumento dos níveis de ureia. Já o consumo de carboidratos não fibrosos apresentou comportamento cúbico em relação aos níveis de ureia. A produção de leite $(27 \mathrm{~kg} / \mathrm{dia})$, a composição físico-química do leite e do queijo de minas frescal, assim como o rendimento do queijo não foram influenciados pela inclusão da ureia na dieta das vacas. Portanto, conclui-se que, para dietas de vacas em lactação, a base de silagem de cana-de-açúcar, com relação volumoso: concentrado 45:55, a ureia pode ser adicionada em até $1,75 \%$ da matéria seca total, sem prejudicar consumo, rendimento, produção, composição físico-química do leite e do queijo de minas frescal.
\end{abstract}

Palavras-chave: bovino, farelo de soja, nitrogênio não proteico, nutrição.

\begin{abstract}
The objective of this work by evaluating consumption, production and processing of milk from cows fed diets containing increasing levels of urea. 8 cows were used $7 / 8$ Holstein / Gir Dairy in two 4x4 Latin squares, each square composed of four diets, four cows and four experimental periods. Diets were formulated to be isonitrogenous, and as forage silage cane sugar. Treatments consisted of increasing levels of urea in place of soybean meal $(0,0.58,1.17,1.75 \%$ of the total DM diet). The intake of dry matter and neutral detergent fiber were not affected by increasing levels of urea. However, crude protein and ether extract decreased linearly with increasing levels of urea. The consumption of non-fiber carbohydrates presented cubic behavior in relation to the levels of urea. The production of milk ( $27 \mathrm{~kg} /$ day), the physico-chemical composition of milk and Minas fresh cheese as well as cheese yield was not affected by the inclusion of urea in the diet of cows. Therefore, it is concluded that, for diets of lactating cows, the sugar cane silage basedr, with forage:concentrate ratio $45: 55$, the urea can be added up to $1.75 \%$ of total dry matter without harming consumption, income, production, physico-chemical composition of milk and Minas cheese.
\end{abstract}

Keywords: bovine, soybean meal, non-protein nitrogen, nutrition.

\section{Introdução}

As despesas com a alimentação contribuem de forma significativa nos custos de produção da atividade leiteira. Entre os itens que compõem a dieta de bovinos leiteiros, os suplementos proteicos são, geralmente, os componentes mais caros. Dessa forma, a utilização de alimentos/ingredientes alternativos que substituam as fontes de proteína comumente utilizadas na alimentação de ruminantes é de grande interesse para a atividade pecuária (Guimarães Júnior et al., 2007).

O uso de nitrogênio não proteico (NNP) como fonte de nitrogênio degradável no rúmen é uma estratégia nutricional bastante comum no Brasil e objetiva a redução dos custos da proteína da dieta, sem alterar a produção de leite. Contudo, a utilização de NNP na dieta pode alterar a composição da proteína do leite, influenciando o processamento industrial da matéria-prima, já que os teores de proteína verdadeira e da caseína têm influência direta sobre a fabricação do queijo (Aquino et al., 2009).

Diversos estudos foram conduzidos nos últimos 30 anos sobre o uso de fontes proteicas para vacas leiteiras, tendo como objetivo maximizar a eficiência de utilização da proteína dietética, melhorar o desempenho animal e reduzir perdas de nitrogênio para o ambiente (Santos et al., 1998). A nutrição proteica dos ruminantes tem como premissa básica disponibilizar ao animal

* Recebido em 4 de dezembro de 2012 e aceito em 8 de abril de 2013.

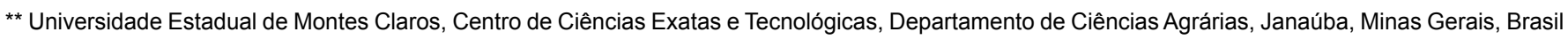
Autor para correspondência: Vicente Ribeiro Rocha Júnior. E-mail: vicente.rocha@unimontes.br 
uma adequada quantidade de proteína degradada no rúmen (PDR), para que ocorra eficiência dos processos digestivos neste compartimento gástrico e, consequentemente, otimizar o desempenho animal com a mínima quantidade de proteína bruta dietética (NRC, 2001). Segundo este comitê, a maximização da eficiência do uso da proteína bruta dietética requer a seleção de alimentos proteicos e suplementos de nitrogênio não proteico, que possam disponibilizar quantidades adequadas de PDR que satisfaçam, mas não excedam as exigências de nitrogênio necessárias para a máxima síntese de proteína bruta microbiana, e, em determinadas situações, utilizar adequadas fontes de proteína não degradada no rúmen (PNDR) para o fornecimento de aminoácidos absorvíveis no intestino delgado em complementação à proteína degradada no rúmen.

Santos et al. (2006) analisaram o efeito da inclusão de níveis crescentes de ureia na dieta de vacas leiteiras do segundo ao sétimo mês de lactação, com produção média de leite no período de $27 \mathrm{~kg} / \mathrm{dia}$. Os níveis de inclusão foram de 0; 0,75; $1,5 \%$ de ureia na MS da dieta, cuja base volumosa era cana-de-açúcar. Nos tratamentos com $0,75 \%$ e $1,5 \%$ de ureia, o consumo médio de ureia foi, respectivamente, de 125 e $243 \mathrm{~g}$ por dia. Não foram observadas diferenças entre os tratamentos quanto ao consumo de matéria seca, produção de leite, produção de leite corrigida para gordura e composição do leite. De acordo com os autores, tais resultados sugerem que o uso de até $1,5 \%$ de ureia na matéria seca da dieta não interfere na produtividade e composição físico-química do leite.

Dessa forma, objetivou-se avaliar a substituição do farelo de soja por níveis crescentes de ureia na dieta de vacas leiteiras, tendo como base volumosa a silagem de cana-de-açúcar, sobre a produção, consumo, composição do leite, bem como a composição e o rendimento de fabricação do queijo de minas frescal.

\section{Material e métodos}

O experimento foi conduzido na Fazenda Lagoa Grande, localizada no Município de Serranópolis de Minas, Norte de Minas Gerais, no período de janeiro a março de 2011. A composição e os parâmetros físico-químicos do leite e queijo de minas frescal foram analisados no Laboratório de Análises de Alimentos e no Laboratório de Tecnologia de Produtos de Origem Animal e Vegetal da UNIMONTES - Campus Janaúba.

Foram utilizadas oito vacas mestiças $7 / 8$ Holandês/Gir com período médio de lactação de $200 \pm 24$ dias. O delineamento experimental adotado foram dois quadrados latinos $4 \times 4$, composto, cada um, de quatro animais, quatro tratamentos e quatro períodos experimentais. As dietas experimentais foram formuladas para vacas com média de $650 \mathrm{~kg}$ de peso vivo e produção de $25 \mathrm{~kg}$ de leite/dia (NRC, 2001), com relação volumoso:concentrado de 45:55, sendo isoproteicas. Os tratamentos consistiram de níveis crescentes de ureia $(0,00 ; 0,58 ; 1,17$ e $1,75 \%$ na MS total da dieta) em substituição ao farelo de soja.

Os animais foram alojados em galpão que contava com baias, bebedouros e comedouros individuais, que possibilitaram a avaliação do consumo de alimentos. O experimento teve duração de 72 dias, sendo dividido em quatro períodos de 18 dias, os primeiros 15 dias de cada período foram reservados para a adaptação dos animais às dietas e os três últimos para coleta de dados, segundo metodologia descrita por Santos et al. (2006).
As dietas foram fornecidas para as vacas duas vezes por dia, às 8 e às 16 horas. Como base volumosa das dietas foi utilizada a silagem de cana-de-açúcar variedade IAC 862480 aditivada com óxido de cálcio (CaO) a $1 \%$ na matéria natural $(\mathrm{MN})$. $\mathrm{O}$ volumoso e concentrado foram pesados e misturados no cocho de cada animal. As sobras do cocho foram pesadas diariamente e registradas, e representavam $10 \%$ da quantidade fornecida. O consumo foi calculado subtraindo-se da quantidade fornecida as sobras dos cochos.

Os alimentos e sobras foram amostrados durante todos os períodos experimentais, sendo as amostras pré-secas em estufa de ventilação forçada $a 5^{\circ} \mathrm{C}$ até que atingisse peso constante, em seguida moídas em moinho de facas com peneira com malha de $1 \mathrm{~mm}$ e analisadas quanto a composição química, para os teores de matéria seca, proteína bruta, extrato etéreo, lignina e matéria mineral, segundo metodologias descritas por Silva e Queiroz (2006). A fibra em detergente neutro e a fibra em detergente ácido, com as devidas correções para a presença do amido, foram determinadas seguindo-se as recomendações de Van Soest et al. (1991). Os teores de compostos nitrogenados insolúveis em detergente neutro (NIDN) e em detergente ácido (NIDA) foram estimados nos resíduos obtidos após extração das amostras nos detergentes neutro e ácido, respectivamente (Van Soest et al., 1991), por intermédio do procedimento de Kjeldahl (AOAC, 1990). Os carboidratos totais (CHOT) foram calculados segundo metodologia descrita por Sniffen et al. (1992), sendo que: $\mathrm{CHOT}=100-(\% \mathrm{~PB}+\% \mathrm{EE}+\% \mathrm{MM})$ e os carboidratos não fibrosos (CNF) foram obtidos subtraindo-se dos $\mathrm{CHOT}$ a fração FDN.

A proporção dos ingredientes utilizados nas dietas e a composição bromatológica das mesmas estão apresentados na Tabela 1 e a composição do volumoso e dos ingredientes dos concentrados estão representados na Tabela 2.

Nos últimos três dias de cada período foram registradas as produções de leite de cada vaca e as produções de leite corrigidas para 3,5\% de gordura foram calculadas utilizando-se a equação proposta por Sklan et al. (1992).

Após a agitação do leite no latão, amostras de leite de cada animal foram coletadas duas vezes ao dia nos últimos três dias de cada período, sendo feito um pool das amostras de leite da ordenha da manhã e da tarde, respeitando-se as mesmas proporções do volume de leite produzido diariamente. As amostras foram coletadas na proporção de $2 / 3$ pela manhã e $1 / 3$ pela tarde e posteriormente essas amostras foram encaminhadas refrigeradas ao laboratório de Tecnologia de Produtos de Origem Animal e armazenadas à temperatura de $5^{\circ} \mathrm{C}$ para análise no mesmo dia.

Para a determinação das características físico-químicas do leite, foram feitas as seguintes análises em duplicata: acidez titulável $\left({ }^{\circ} \mathrm{D}\right)$, que foi realizada com uso da solução indicadora de fenolftaleína $(0,1 \%)$; índice crioscópico $\left({ }^{\circ} \mathrm{H}\right)$, utilizando o aparelho LAKTRON $312-\mathrm{L}$; densidade a $15^{\circ} \mathrm{C}$ utilizando o do termolactodensímetro de Quevenne; teor percentual de gordura pelo método de Gerber; teor percentual de proteína utilizando o método de Kjeldahl com multiplicação do percentual de nitrogênio pelo fator 6,38 ; resíduo mineral pela incineração na Mufla a $550^{\circ}$; os sólidos totais foram obtidos a partir do disco de Ackermann e lactose pela diferença dos demais componentes (BRASIL, 2006). 
Tabela 1: Proporção em ingredientes e composição bromatológica das dietas, na base da matéria seca

\begin{tabular}{|c|c|c|c|c|}
\hline \multirow{2}{*}{ Ingredientes } & \multicolumn{4}{|c|}{ Níveis de inclusão de ureia (\% MS) } \\
\hline & $0,00 \%$ & $0,58 \%$ & $1,17 \%$ & $1,75 \%$ \\
\hline Silagem de cana & 45,00 & 45,00 & 45,00 & 45,00 \\
\hline Farelo de soja & 20,00 & 16,03 & 12,20 & 8,33 \\
\hline Milho grão & 33,60 & 36,89 & 40,00 & 43,14 \\
\hline Ureia: sulfato de amônio (9:1) & 0,00 & 0,58 & 1,17 & 1,75 \\
\hline Suplemento mineral ${ }^{1}$ & 1,4 & 1,5 & 1,65 & 1,78 \\
\hline \multicolumn{5}{|c|}{ Composição Bromatológica } \\
\hline Matéria Seca (\%) & 49,40 & 50,29 & 49,85 & 48,82 \\
\hline Matéria orgânica (\%) & 97,06 & 93,7 & 97,1 & 97,43 \\
\hline Proteína Bruta (\%) & 13,28 & 13,70 & 13,04 & 13,68 \\
\hline $\mathrm{NIDN}^{2}$ & 0,29 & 0,21 & 0,23 & 0,23 \\
\hline $\mathrm{NIDA}^{3}$ & 0,06 & 0,05 & 0,05 & 0,05 \\
\hline Extrato Etéreo (\%) & 2,45 & 1,82 & 1,73 & 1,35 \\
\hline Carboidratos Totais (\%) & 60,91 & 61,83 & 62,93 & 65,14 \\
\hline Carboidratos não fibrosos (\%) & 41,50 & 42,61 & 43,64 & 44,67 \\
\hline Fibra em detergente neutro (\%) & 43,97 & 41,39 & 47,99 & 36,42 \\
\hline Fibra em detergente ácido (\%) & 16,85 & 16,44 & 16,19 & 17,89 \\
\hline Lignina (\%) & 1,47 & 1,46 & 1,43 & 1,42 \\
\hline
\end{tabular}

Tabela 2: Teores de matéria seca (MS), proteína bruta (PB), fibra em detergente neutro (FDN), fibra em detergente ácido (FDA), extrato etéreo (EE) e lignina dos alimentos

\begin{tabular}{lcccccc}
\hline Nutrientes & MS & PB & FDN & FDA & EE & Lignina \\
\hline Ingredientes & & \multicolumn{5}{c}{$\%$ Matéria Seca } \\
\hline Silagem de cana & 28,68 & 3,88 & 61,79 & 36,89 & 1,38 & 1,30 \\
Milho & 90,74 & 13,51 & 14,20 & 4,38 & 3,17 & 1,34 \\
Farelo de soja & 89,12 & 48,04 & 15,18 & 9,23 & 1,55 & 1,48 \\
\hline
\end{tabular}

O queijo de minas frescal foi processado de acordo com a técnica recomendada por Furtado \& Lourenço Neto (1994). No último dia de coleta, o leite de cada dieta experimental foi separado, pesado, filtrado e submetido à pasteurização lenta a $65^{\circ} \mathrm{C}$ por 30 minutos. Após este tratamento térmico, o leite foi resfriado a $39{ }^{\circ} \mathrm{C}$, temperatura em que foram adicionados $40 \mathrm{~mL} / 100 \mathrm{~L}$ da solução aquosa de cloreto de cálcio na concentração de $50 \%$ e $30 \mathrm{~mL} / 100 \mathrm{Lde}$ agente coagulante (coalho líquido $\mathrm{Ha}$ $\mathrm{La}\left(\mathbb{B}_{)}\right.$. Após 40 a 60 minutos, ocorreu a coagulação do leite. Em seguida, foi feito o corte da massa com uma faca inox em cubos de 1,5 a $2 \mathrm{~cm}$, intercalando a mexedura e o repouso para promover a dessoragem, que foi seguida da drenagem do soro e da salga da massa ( $700 \mathrm{~g} / 100 \mathrm{~L}$ de sal branco refinado). Os queijos foram deixados nas fôrmas por 1 hora com tempo de viragem de 30 minutos, sendo, então, embalados e pesados em balança digital para determinação do rendimento e conservados a $4^{\circ} \mathrm{C}$. O rendimento bruto dos queijos foi calculado segundo a equação (Andreatta et al., 2009): Rendimento bruto $(\mathrm{kg} / \mathrm{kg})=$ peso da formulação (leite mais os ingredientes) $(\mathrm{kg}) /$ massa de queijo após embalagem $(\mathrm{kg})$. O rendimento ajustado para o teor de umidade do queijo (Lucey \& Kelly, 1994) foi calculado considerando-se um valor de $57 \%$ como referência para a umidade do queijo de minas frescal, conforme sugerido por Oliveira (1986).

Amostras do queijo de minas frescal foram analisadas em duplicata quanto ao $\mathrm{pH}$, utilizando-se o peagamêtro digital, acidez titulável $\left({ }^{\circ} \mathrm{D}\right)$, gordura pelo método butirométrico, resíduo mineral fixo, pela eliminação da matéria orgânica à temperatura de $550^{\circ} \mathrm{C}$, sólidos totais através da evaporação de água da amostra com utilização da estufa a $105^{\circ} \mathrm{C}$.

Os dados relativos ao consumo de nutrientes, composição físico-química do leite e do queijo foram submetidos à análise de variância e regressão, utilizando-se o programa SISVAR (Ferreira, 2011). Os critérios utilizados para a escolha do modelo foram o coeficiente de determinação $\left(R^{2}\right)$ e a significância observada por meio do teste $\mathrm{F}$, ao nível de $5 \%$ de significância.

\section{Resultados e discussão}

O consumo de matéria seca e FDN (Tabela 3) não foram afetados pelos níveis crescentes de ureia em substituição ao farelo de soja $(P>0,05)$. Entretanto, o consumo de proteína bruta e extrato etéreo reduziram linearmente com o aumento dos níveis de ureia $(P<0,05)$. Certamente a redução numérica do consumo de matéria seca foi suficiente para diminuir os consumo de proteína bruta e extrato etéreo. Já o consumo de carboidratos não fibrosos apresentou comportamento cúbico em relação aos níveis de ureia na dieta de vacas em lactação.

Aquino et al. (2007) citaram que a ureia, adicionada ao concentrado em níveis de até $1,5 \%$ na MS da dieta e fornecida na dieta completa, não alterou o consumo de MS de vacas leiteiras. Em alguns trabalhos (Costa, 2004; Oliveira, 2005) quando o percentual do concentrado em dietas à base de cana-de-açúcar chegou a $60 \%$, na base seca, verificaram-se consumo de MS semelhantes aos encontrados nesta pesquisa. Os valores preconizados pelo NRC (2001) para o consumo de matéria seca de vaca leiteira pesando $600 \mathrm{~kg}$ de peso corporal, produzindo $20 \mathrm{~kg}$ de leite corrigido para $3,5 \%$ de gordura e ganhando $0,300 \mathrm{~kg} / \mathrm{dia}$ é de $18,30 \mathrm{~kg} / \mathrm{dia}$ e $3,05 \%$ do peso corporal. Nesta pesquisa, o consumo médio de matéria seca foi de $22,66 \mathrm{~kg} / \mathrm{dia}$, correspondendo a $3,48 \%$ do peso corporal, para vacas com produção média de $27 \mathrm{~kg} / \mathrm{dia}$.

Guimarães Júnior et al. (2007) verificaram que o consumo de matéria seca está associado à degradação do NNP, 
Tabela 3: Consumo de matéria seca (CMS), proteína bruta (CPB), extrato etéreo (CEE), carboidratos não fibrosos (CCNF), fibra em detergente neutro (CFDN), equações de regressão (ER) e coeficientes de variação (CV) de vacas em lactação submetidas a dietas com níveis crescentes de ureia

\begin{tabular}{lccccccc}
\hline & \multicolumn{9}{c}{ Níveis de inclusão de ureia } & & \\
\cline { 2 - 6 } \multicolumn{1}{c}{ Variáveis } & $\mathbf{0 , 0 0 \%}$ & $\mathbf{0 , 5 8} \%$ & $\mathbf{1 , 1 7 \%}$ & $\mathbf{1 , 7 5 \%}$ & ER & CV (\%) \\
\hline CMS (kg/dia) & 23,13 & 22,84 & 22,88 & 21,58 & $\hat{Y}=22,66$ & 10,72 \\
CPB (kg/dia) & 4,56 & 3,54 & 3,11 & 3,33 & 1 & 11,7 \\
CEE (kg/dia) & 0,71 & 0,53 & 0,29 & 0,39 & 2 & 16,19 \\
CCNF (kg/dia) & 8,68 & 11,03 & 10,14 & 11,32 & 3 & 18,42 \\
CFDN (kg/dia) & 7,45 & 6,55 & 5,8 & 7,08 & $\hat{Y}=6,72$ & 23,41 \\
$1 \hat{Y}=0,7085-4,2543 X$ & & & & & & & \\
$2 \hat{Y}=0,2078-0,6600 X$ & & & & & & & \\
$3 \hat{Y}=8,6750+9,8245 X^{2}+4,4481 X^{3}$ & & & & & & & \\
\hline
\end{tabular}

Os resultados obtidos de produção de leite, com ou sem correção de gordura e parâmetros físico-químicos do leite (Tabela 4) e do queijo (Tabela 5) não sofreram $(P>0,05)$ influência dos níveis crescentes de ureia adicionados à dieta em substituição ao farelo de soja.

Santos et al. (2006) não observaram diferenças para produção de leite, produção de leite corrigida para gordura e composição do leite, analisando o efeito da inclusão de níveis crescentes de ureia $(0,0,75$ e $1,5 \%$ na MS da dieta) em dietas de vacas leiteiras do segundo ao sétimo mês de lactação, com produção média de leite no período de $22,7 \mathrm{~kg} / \mathrm{dia}$, onde a base volumosa utilizada também foi a silagem de cana-de-açúcar.

Pina et al. (2006) avaliaram a utilização que corresponde a $100 \%$, logo proporções adequadas de carboidratos de rápida e média fermentação maximizam a utilização da ureia, o que, por sua vez, aumenta a digestibilidade da fibra da dieta, por aumento dos micro-organismos ruminais. Consequentemente, ocorre um aumento na taxa de passagem dos alimentos, favorecendo o consumo de matéria seca, já que o rúmen esvazia mais rapidamente.

Caldas Neto et al. (2008) também não observaram variação no consumo de matéria seca, em função dos níveis de inclusão de ureia $(0 ; 0,1 ; 0,3$ e $0,9 \%$ da MS total da dieta) utilizando farinha de varredura de mandioca como fonte de energia. Isso pode ser explicado pelo fato de ocorrer maior disponibilidade de nitrogênio no rúmen, que quando associado à energia de rápida liberação proveniente da farinha de varredura, favorece o desenvolvimento microbiano e a eficiência de utilização do nitrogênio disponível.

Magalhães et al. (2003) também não notaram diferença no consumo de FDN (em média 1,08\% PV) quando forneceram dietas com níveis crescentes de ureia $(0$; 0,$65 ; 1,30$ e $1,95 \%$ da MS total). O consumo médio de FDN encontrado foi em torno de 1,03 $\%$ do peso vivo, concordando assim com valores sugeridos na literatura. Para Mertens (1992), a ingestão ótima de FDN para vacas em lactação é em torno de $1,2 \%$ do peso vivo. Provavelmente, os níveis de proteína degradável no rúmen das quatro dietas experimentais foram suficientes para promoverem uma adequada digestão ruminal, mantendo assim o mesmo nível de consumo.
Tabela 4: Produção de Leite, densidade $\left(15^{\circ} \mathrm{C}\right)$, índice crioscópico, acidez Dornic, gordura, proteína bruta, lactose, resíduo mineral fixo, sólidos totais, média e coeficientes de variação $(\mathrm{CV})$ do leite de vacas submetidas a dietas com níveis crescentes de ureia de ureia em até $5 \%$ da MS do concentrado, o que permitiu observar a possibilidade de maior inclusão de nitrogênio não proteico proveniente desta fonte em dietas para vacas lactantes. Esses autores não encontraram diferença significativa para produção e composição do leite e eficiência de utilização da matéria seca e do nitrogênio para síntese de leite para a dieta com elevado teor de ureia em relação à dieta controle, contendo farelo de soja.

\begin{tabular}{|c|c|c|c|c|c|c|}
\hline \multirow[b]{2}{*}{ Variáveis } & \multicolumn{4}{|c|}{ Níveis de Inclusão de ureia (\%) } & \multirow[b]{2}{*}{ Média } & \multirow[b]{2}{*}{$\mathrm{CV}(\%)$} \\
\hline & 0,00 & 0,58 & 1,17 & 1,75 & & \\
\hline Produção de leite (Kg/dia) & 27,50 & 27,91 & 27,89 & 24,73 & $\hat{Y}=27,00$ & 4,64 \\
\hline PLCG $-3,5 \%$ de gordura $(\mathrm{Kg} / \mathrm{dia})^{1}$ & 29,47 & 28,53 & 25,91 & 28,70 & $\hat{Y}=28,15$ & 15,32 \\
\hline Densidade (g/mL) & 1,031 & 1,031 & 1,031 & 1,031 & $\hat{Y}=1,031$ & 5,24 \\
\hline Índice Crioscópico $\left({ }^{\circ} \mathrm{H}\right)$ & $-0,548$ & $-0,549$ & $-0,556$ & $-0,550$ & $\hat{Y}=-0,551$ & 3,34 \\
\hline Acidez Dornic $\left({ }^{\circ} \mathrm{D}\right)$ & 19,50 & 19,63 & 20,00 & 19,75 & $\hat{Y}=19,72$ & 6,59 \\
\hline Gordura (\%) & 3,63 & 3,51 & 3,56 & 3,43 & $\hat{Y}=3,53$ & 15,04 \\
\hline Proteína Bruta (\%) & 3,23 & 3,94 & 3,29 & 3,23 & $\hat{Y}=3,42$ & 20,92 \\
\hline Lactose (\%) & 4,73 & 4,77 & 4,77 & 4,67 & $\hat{Y}=4,74$ & 4,42 \\
\hline Resíduo Mineral Fixo (\%) & 0,69 & 0,71 & 0,68 & 0,72 & $\hat{Y}=0,70$ & 10,97 \\
\hline Sólidos Totais (\%) & 8,98 & 9,05 & 9,04 & 8,48 & $\hat{Y}=8,89$ & 6,68 \\
\hline
\end{tabular}

${ }^{1}$ PLCG- produção de leite corrigida para gordura.
Quanto ao teor de gordura do leite, as amostras apresentaram valores percentuais superiores $(3,53 \%)$ ao estabelecido pela legislação (mínimo de $3 \%$ ), e foram similares aos obtidos por Vilela et al. (2003), de 3,5\%, em estudo sobre diferentes suplementos para vacas mestiças em lactação alimentadas com cana-de-açúcar. Aquino et al. (2007), por sua vez, encontraram 
níveis médios de gordura do leite variando de 2,97 a $3,17 \%$, em estudo sobre efeito de níveis crescentes de ureia na dieta de vacas em lactação, enquanto Carmo et al. (2005) verificaram aumento no teor de gordura no leite dos animais alimentados com dieta contendo ureia em substituição parcial ao farelo de soja.

O teores médios da proteína encontradas variaram de $3,23 \%$ a $3,94 \%$, sendo semelhantes aos descritos por Aquino et al. (2009), que encontraram teores médios de proteína do leite variando de $3,45 \%$ a $3,66 \%$, e sugeriram que a adição de até $1,5 \%$ de ureia na dieta de vacas no meio da lactação não altera a capacidade de produção de proteína microbiana no rúmen, além de atender às necessidades de proteína metabolizável. O uso do NNP em substituição à proteína verdadeira, aliada ao fornecimento de uma fonte de energia prontamente disponível, como a proveniente da cana-de-açúcar, parece ser viável para animais com produção de leite de até $25 \mathrm{~kg}$. Resultados similares ao descrito foram encontrados por Carmo et al. (2005), os quais relataram que a adição da ureia e fontes de proteína degradável no rúmen não altera o teor de proteína do leite. Segundo Paixão et al. (2006), isso ocorre em virtude da capacidade dos micro-organismos do rúmen de converter o NNP em proteína de alto valor biológico.

Broderick et al. (1993) sugeriram que a ausência de efeito negativo em termos de produção de proteína do leite em vários estudos, quando se incluiu ureia em dietas para vacas leiteiras, indicou que a proteína metabolizável não foi limitante no tratamento com ureia. Os dados do trabalho de Carmo et al. (2005) concordam com os autores supracitados e apontam igual eficiência da ureia em suprir aminoácidos para a síntese proteica na glândula mamária de vacas no terço final de lactação em relação ao farelo de soja (quando incluída na dieta na proporção de até $2 \%$ da MS).

O teores de sólidos do leite é de extrema importância principalmente para a indústria láctea, pois aumenta o rendimento de produtos derivados do leite. O valor médio de sólidos encontrado foi de $8,89 \%$ e o resultado difere dos encontrados por Carmo et al. (2005), em estudo sobre a substituição do farelo de soja por ureia ou amireia para vacas, onde descreveram maiores teores de sólidos totais no leite com valor médio de 11,92 para animais alimentados com dietas contendo $2 \%$ de ureia.

Há escassez de trabalhos que avaliam a influência da nutrição sobre os derivados lácteos, porém os valores de $\mathrm{pH}$ encontrados, com variação de 6,40 a 6,56, para o queijo de minas frescal está diretamente relacionado com a aceitação do produto pelo consumidor, que deve ser confirmada por meio de um teste de análise sensorial.

Em relação aos teores de gordura do queijo, verificaram-se valores médios de $11,09 \%$. Esses resultados podem estar associados ao processamento, pois valores normais de gordura foram encontrados para o leite utilizado como matéria-prima para fabricação do queijo de minas frescal.

Foi encontrado percentual médio de proteína bruta de $17,28 \%$, sendo a proteína indicativo do rendimento para fabricação do queijo e quanto maior o teor de caseínas, maior será o rendimento. O teor proteína bruta do leite de 3,42\% (Tabela 4) pode ter contribuído para o elevado rendimento bruto do queijo produzido com valores médios de $20,09 \%$. O uso do NNP em substituição a proteína verdadeira, aliada ao fornecimento de uma fonte de energia prontamente disponível, como a proveniente da silagem de cana-de-açúcar, parece ser viável para animais com produção de leite próxima a $25 \mathrm{~kg} / \mathrm{dia}$.

Segundo Emmons, Dubé \& Modler (2003), no tocante ao rendimento de fabricação dos queijos, a ausência de diferenças entre a concentração de proteína verdadeira e, especialmente de caseína na matéria-prima utilizada, explica a ausência de efeito da inclusão de ureia na dieta sobre o rendimento bruto, já que essa é a principal responsável pelo rendimento de fabricação.

Como a composição dos queijos também não sofreu diferenças significativas, o rendimento ajustado teve o mesmo comportamento do rendimento bruto em função das dietas utilizadas.

\section{Conclusões}

Em dietas de vacas em lactação, a base de silagem de canade-açúcar, com relação volumoso:concentrado de 45:55, a ureia pode ser adicionada em até $1,75 \%$ da matéria seca da dieta, sem prejudicar o consumo, produção e composição físicoquímica do leite.

A inclusão de ureia em até $1,75 \%$ da matéria seca da dieta não compromete o rendimento para produção de queijo de minas frescal e a composição físico-química do mesmo.

\section{Agradecimentos}

À Fapemig e ao CNPq. Ao Senhor Auller Coelho, proprietário da Fazenda Lagoa Grande - Município de Serranópolis de Minas. 


\section{Referências}

ANDREATTA, E.; FERNANDES, A.M.; SANTOS, M.V. et al. Quality of Minas frescal cheese prepared from milk with different somatic cell counts. Pesquisa Agropecuária Brasileira, v. 44, p. 320-326, 2009.

AOAC (Association of Official Analytical Chemist) Official Methods of Analysis, Association of Official Analytical Chemists. 15th Ed. Gaithersburg, USA: AOAC Press; 1990.

AQUINO, A. A.; BOTARO, B. G.; IKEDA, F. S. et al. Efeito de níveis crescentes de ureia na dieta de vacas em lactação sobre a produção e a composição físico-química do leite. Revista Brasileira de Zootecnia. v. 36, n. 4, p. 881-887, 2007.

AQUINO, A. A.; PEIXOTO JUNIOR. K. C.; GIGANTE, M. L. Efeito de níveis crescentes de ureia na dieta de vacas leiteiras sobre a composição e rendimento de fabricação de queijos de minas frescal. Brazilian Journal of Veterinary Research and Animal Science. São Paulo, v. 46, n. 4, p. 273-279, 2009.

BRASIL. Ministério da Agricultura, Pecuária e Abastecimento. Métodos analíticos oficiais físico-químicos para controle de leite e produtos lácteos. Instrução Normativa $n^{\circ} .22$ de 14 de dezembro de 2006. Diário Oficial da União, Brasília, DF, 2006. Disponível em: <http://www.agricultura.gov.br>. Acesso em: 17 novembro 2012.

BRASIL. Ministério da Agricultura, Pecuária e Abastecimento. Regulamento Técnico de Identidade e Qualidade do Leite tipo A, Leite tipo B, Leite tipo C, Leite Pasteurizado e Leite Cru Refrigerado. Instrução Normativa $n^{\circ} 51$ de 18 de setembro de 2002.

BRODERICK, G.A. et al. Urea versus true protein as supplement for lactating dairy cows fed grains plus mixtures of alfafa and corn silages. Journal Dairy Science, Savoy, v. 76, p. 2266-2274, 1993.

CALDAS NETO, S.F.; ZEOULA, L.M. PRADO, I.N. et al. Proteína degradável no rúmen na dieta de bovinos: digestibilidades total e parcial dos nutrientes e parâmetros ruminais. Revista Brasileira de Zootecnia, Viçosa, v. 37, n. 6, p. 1094-1102, 2008.

CARMO, C. A.; SANTOS, F. A .P.; IMAIZUMI, H. et al. Substituição do farelo de soja por ureia ou amireia para vacas em final de lactação. Acta Scientiarum, v. 27, n. 2, p. 277-286, 2005.

CORREA, C.E.S.; PEREIRA, M.N.; OLIVEIRA, S.G. et al. Performance of Holstein cows fed sugarcane or corn silages of different grain textures. Scientia Agricola, v. 60, n. 4, p. 621-629, 2003.

COSTA, M. G. Cana-de-açúcar e concentrados em diferentes proporções para vacas leiteiras. 2004. 66 f. Dissertação (Mestrado em Zootecnia) - Universidade Federal de Viçosa, Viçosa, 2004.

DEMARCCHI, J. O uso da cana-de-açúcar como recurso forrageiro. In: SIMPÓSIO DE MANEJO DE PASTAGENS, 18., 2001, Piracicaba. Anais... Piracicaba: Escola Superior de Agricultura Luiz de Queiroz, 2001. p. 84

FERREIRA, D. F. . SISVAR: a computer statistical analysis system. Ciência e Agrotecnologia (UFLA), v. 35, n. 6, p. 1039-1042, 2011.

FURTADO, M.M.; LOURENÇO NETO, J.P.M. Tecnologia de queijos: manual técnico para produção industrial de queijos. São Paulo: Dipemar, 1994. 118 p.

GUIMARÃES JUNIOR, R.; PEREIRA, L.G.R.; TOMICH, T.R.et al. Ureia na alimentação de vacas leiteiras. Planaltina, D.F.: Embrapa Cerrados, 2007, 33 p.

LUCEY, J.; KELLY, J. Cheese yield. Journal of the Society of Dairy Technology, v. 47, n. 1, p. 1-14, 1994.

MAGALHÃES, A.L.R.; CAMPOS, J.M.S.; VALADARES FILHO, S.C. et al. Cana-de-açúcar em substituição à silagem de milho em dietas para vacas em lactação: desempenho e viabilidade econômica. Revista Brasileira de Zootecnia, v. 33, n. 5, p. 12921302, 2004.
NATIONAL RESEARCH COUNCIL - NRC. Nutrient requirements of dairy cattle. 7. ed. Washington, DC: National Academic Press, 2001. $381 \mathrm{p}$.

OLIVEIRA, A. S. Casa de café ou casa de soja em substituição ao milho em dietas à base de cana-de-açúcar para vacas leiteiras. 2005. 97 f. Dissertação (Mestrado em Zootecnia) - Universidade Federal de Viçosa, Viçosa, 2005.

OLIVEIRA, J.S. Queijo: fundamentos tecnológicos. 2.ed. Campinas: Unicamp, 1986. 146 p.

OLIVEIRA, M.M.N.F.; TORRES, C.A.A.; VALADARES FILHO, S.C. et al. Ureia para vacas leiteiras no pós-parto: desempenho produtivo e reprodutivo. Revista Brasileira de Zootecnia v. 33, p. 2266-2273, 2004.

PAIXÃO, M.L; VALADARES FILHO, S. C; LEÃO, M. I. et al. Uréia em dietas para bovinos: consumo, digestibilidade dos nutrientes, ganho de peso, características de carcaça e produção microbiana. Revista Brasileira de Zootecnia, v. 35, n. 6, p. 2451-2460, 2006.

PINA, D.S.; VALADARES FILHO, S.C.; VALADARES, R.F.D. et al.Consumo e digestibilidade aparente total dos nutrientes, produção e composição do leite de vacas alimentadas com dietas contendo diferentes fontes de proteína. Revista Brasileira de Zootecnia, v. 35, n. 4, p. 1543-1551, 2006.

Santos FAP, Huber JT, Theurer CB, Swingle RS, Simas JM, Chen $\mathrm{KH}$, et al. Milk yield and composition of lactating cows fed steamflaked sorghum and graded concentrations of ruminally degradable protein. Journal Dairy Science 1998, p. 81-215-20.

SANTOS, F. A. P. Metabolismo de proteínas. In: BERCHIELLI, T. T.; PIRES, A. V.; OLIVEIRA, S. G. (Ed.). Nutrição de ruminantes. Jaboticabal: Fundep, p. 255-286, 2006.

SANTOS, F.A.P.; CARMO, C.A.; MARTINEZ, J.C. et al. Desempenho de vacas em lactação recebendo dietas com diferentes teores de amido total, acrescidas ou não de levedura (Saccharomyces cerevisiae). Revista Brasileira de Zootecnia, v. 35, n. 4, p. 1568-1575, 2006.

SILVA, D. J.; QUEIROZ, A. C. Análise de Alimentos: métodos químicos e biológicos. 3. ed. Viçosa: UFV, 2006.

SILVA, R. M. N; VALADARES, R. F. D.; VALADARES FILHO, S. C.; CECON, P. R.; CAMPOS, J. M. S.; OLIVEIRA, G. A.; OLIVEIRA, A. S. Ureia para vacas em lactação. 1. Consumo, Digestibilidade, Produção e Composição do Leite. Revista Brasileira de Zootecnia, Viçosa, v. 30, n. 5, p. 1639-1649, 2001.

SKLAN, D. R. et al. Fatty acids, calcium soaps of fatty acids, and cottonseeds fed to high yielding cows. Journal of Dairy Science, Champaign, v. 75, n. 9, p. 2463-2472, 1992.

SNIFFEN, C.J.; O'CONNOR, J.D.; VAN SOEST, P.J. A net carbohydrate and protein system for evaluating cattle diets. II. Carbohydrate and protein availability. Journal of Animal Science, v. 70, p. 3562-3577, 1992.

SOUZA, R.C. Adição crescente de ureia na cana-de-açúcar (Saccharum officinarum L.) in natura na dieta de vacas em lactação. Dissertação (Doutorado em Zootecnia)- Universidade Federal de Minas Gerais, Escola de Veterinária, pág. 121, 2011.

VAN SOEST, P.J.; ROBERTSON, J.B.; LEWIS, B.A. Methos for extraction fiber, neutral detergent fiber and nonstarch polysaccarides in relation to animal nutrition cows. Journal of Dairy Science, v. 83, n. 1, p. 3583-3597, 1991.

VILELA, M. S.; FERREIRA, M. A.; VÉRAS, A. S. C. et al. Avaliação de diferentes suplementos para vacas mestiças em lactação alimentadas com cana-de-açúcar: Desempenho e Digestibilidade. Revista Brasileira de Zootecnia. v. 32, n. 3, p. 768-777, 2003. 